\title{
Mind the gap: what explains the rural- nonrural inequality in diarrhoea among under-five children in low and medium- income countries? A decomposition analysis
}

\author{
A. F. Fagbamigbe ${ }^{1,2,3^{*}}$ (D, F. F. Oyinlola ${ }^{4}$, O. M. Morakinyo ${ }^{5}$, A. S. Adebowale ${ }^{1}$, O. S. Fagbamigbe 6,7 and A. O. Uthman ${ }^{2}$
}

\begin{abstract}
Background: Diarrhoea poses serious health problems among under-five children (U5C) in Low-and Medium-Income Countries (LMIC) with a higher prevalence in rural areas. A gap exists in knowledge on factors driving rural-non-rural inequalities in diarrhoea development among U5C in LMIC. This study investigates the magnitude of rural-non-rural inequalities in diarrhoea and the roles of individual-level and neighbourhood-level factors in explaining these inequalities.

Methods: Data of 796,150 U5C, from 63,378 neighbourhoods across 57 LMIC from the most recent Demographic and Health Survey (2010-2018) was analysed. The outcome variable was the recent experience of diarrhoea while independent variables consist of the individual- and neighbourhood-level factors. Data were analysed using multivariable Fairlie decomposition at $p<0.05$ in Stata Version 16 while visualization was implemented in R Statistical Package.

Results: Two-thirds (68.0\%) of the children are from rural areas. The overall prevalence of diarrhoea was $14.2,14.6 \%$ vs $13.4 \%$ among rural and non-rural children respectively $(p<0.001)$. From the analysis, the following 20 countries showed a statistically significant pro-rural inequalities with higher odds of diarrhoea in rural areas than in nonrural areas at $5 \%$ alpha level: Albania ( $\mathrm{OR}=1.769 ; p=0.001)$, Benin $(\mathrm{OR}=1.209 ; p=0.002)$, Burundi $(\mathrm{OR}=1.399 ; p<0.001)$, Cambodia $(\mathrm{OR}=1.201$; $p<0.031)$, Cameroon $(\mathrm{OR}=1.377 ; p<0.001)$, Comoros $(\mathrm{OR}=1.266 ; p=0.029)$, Egypt $(\mathrm{OR}=1.331 ; \mathrm{p}<0.001)$, Honduras $(\mathrm{OR}=1.127 ; p=0.027)$, India ( $\mathrm{OR}=1.059 ; p<0.001)$, Indonesia $(\mathrm{OR}=1.219 ; p<0.001)$, Liberia $(\mathrm{OR}=1.158 ; p=0.017)$, Mali $(\mathrm{OR}=1.240 ; p=0.001)$, Myanmar ( $\mathrm{OR}=1.422 ; p=0.004)$, Namibia $(\mathrm{OR}=1.451 ; p<0.001)$, Nigeria $(\mathrm{OR}=1.492 ; p<0.001)$, Rwanda (OR=1.261; $p=0.010)$, South Africa ( $O R=1.420 ; p=0.002)$, Togo $(O R=1.729 ; p<0.001)$, Uganda $(O R=1.214 ; p<$ $0.001)$, and Yemen $(\mathrm{OR}=1.249 ; \mathrm{p}<0.001)$; and pro-non-rural inequalities in 9 countries. Variations exist in factors associated with pro-rural inequalities across the 20 countries. Overall main contributors to pro-rural inequality were neighbourhood socioeconomic status, household wealth status, media access, toilet types, maternal age and education.

(Continued on next page)
\end{abstract}

\footnotetext{
* Correspondence: franstel74@yahoo.com

'Department of Epidemiology and Medical Statistics, Faculty of Public Health, College of Medicine, University of Ibadan, Ibadan, Nigeria

${ }^{2}$ Division of Health Sciences, Populations, Evidence and Technologies Group, Warwick Medical School, University of Warwick, Coventry, UK

Full list of author information is available at the end of the article
}

(c) The Author(s). 2021 Open Access This article is licensed under a Creative Commons Attribution 4.0 International License, which permits use, sharing, adaptation, distribution and reproduction in any medium or format, as long as you give appropriate credit to the original author(s) and the source, provide a link to the Creative Commons licence, and indicate if changes were made. The images or other third party material in this article are included in the article's Creative Commons licence, unless indicated otherwise in a credit line to the material. If material is not included in the article's Creative Commons licence and your intended use is not permitted by statutory regulation or exceeds the permitted use, you will need to obtain permission directly from the copyright holder. To view a copy of this licence, visit http://creativecommons.org/licenses/by/4.0/. The Creative Commons Public Domain Dedication waiver (http://creativecommons.org/publicdomain/zero/1.0/) applies to the data made available in this article, unless otherwise stated in a credit line to the data. 
(Continued from previous page)

Conclusions: The gaps in the odds of diarrhoea among rural children than nonrural children were explained by individual-level and neighbourhood-level factors. Sustainable intervention measures that are tailored to country-specific needs could offer a better approach to closing rural-non-rural gaps in having diarrhoea among U5C in LMIC.

Keywords: Diarrhoea, Rural-non-rural inequalities, Decomposition, Fairlie multivariable decomposition, Low- and middleincome countries

\section{Background}

Diarrhoea remains a disease of major public health challenge among under-five children (U5C) across the low and middle-income countries (LMIC) [1-3]. It is a gastrointestinal infection triggered by a pathogenic microorganism that increases the frequency of watery stools for more than three or four times a day [4,5]. It is the second leading cause of deaths among U5C across the world. Globally, diarrhoea occurs in about 1.7 billion children yearly with 525,000 deaths $[6,7]$. In LMIC, U5C experience up to 5 episodes of diarrhoea in a year $[4,8]$ with high incidence and case-fatality ratios [9]. Specifically, more than half of the deaths caused by diarrhoea were recorded in Nigeria, India, Pakistan, Afghanistan, and Ethiopia [5].

Globally, morbidity and mortality caused by diarrhoea have reduced in advanced countries, on the contrary, it's still a major issue of concern among the U5C in the LMIC $[10,11]$. However, there was a significant decline in the number of childhood deaths due to diarrhoea from approximately 1.6 million in 1990 to 450,000 in 2016 in LMIC [12]. To achieve a further reduction in mortality to less than 1 per 1000 live births as proposed jointly by the WHO and UNICEF, it will require a context-specific grasp of the decomposition of the drivers of diarrhoea diseases at both urban and rural settings [13].

Epidemiologic studies have shown that factors that predispose children to diarrhoea are a complex interaction between socio-economic, environmental, and behavioural variables [14-17]. Diarrhoea-related morbidity and mortality among U5C have been linked to poor hygiene and sanitation practices $[1,18]$, limited access to improved sources of drinking water [3, 14], socioeconomic status, education level, place of residence [9], inappropriate breastfeeding [17, 18], zinc deficiency [19] and other immediate household and environmental characteristics $[5,8,14]$ The higher prevalence of diarrhoea in the LMIC has been attributed to the standard of living which differs across the rural-non-rural differences in place of residence [20].

Health disparities between children living in urban and rural regions do exist due to the differences in the level of major determinants. There is ample evidence that suggests that urban areas have better health outcomes than rural areas in LMIC [2]. Consequently, the determinants of childhood diarrhoea could be country or regionally-specific based on the difference in the living environment. Household-level and neighbourhood-level factors may be important in clarifying rural-non-rural differences in diarrhoea morbidity and mortality. This, however, calls for immediate research to understanding the decomposition effect of rural-non-rural difference in the place of residence on diarrhoea episodes among U5C in LMIC.

Although the literature is replete on the risk factors of diarrhoea, there is a dearth of information on the decomposition of factors associated with the development of diarrhoea based on place of residence in LMIC. Hence, this study was designed to address this gap. Having good knowledge of the core individual-level and neighbourhood-level factors driving rural-non-rural health disparities would assist LMIC in planning appropriate intervention measures aimed at improving population health outcomes and reducing the burden of diarrhoea among U5C.

\section{Methods}

\section{Study design and data}

The data from the Demographic and Health Surveys (DHS) collected periodically across the LMIC was used in this study. The ICF Macro, the USA in conjunction with the ministry of health, the office of statistics, and the population commissions in respective LMIC conduct the periodical cross-sectional nationally representative population-based household DHS. We pooled data from the most recent DHS conducted within the last ten years (2010-2018) and available as of April 2020 and which provided information on diarrhoea among U5C. Only 57 LMIC met these inclusion criteria and were included in this study. We analysed data of 796,150 U5C, from 63, 378 neighbourhoods across the 57 LMIC. In each of the countries, DHS used a multi-stage (usually from states/ divisions/regions to the district to clusters), stratified sampling design. The households (the sampling units) are selected from the clusters known as the primary sampling units (PSU) [21, 22]. We applied sampling weights provided in the data to all our analysis. This was to adjust for unequal cluster sizes and to ensure that our findings adequately represent the target population. The 
DHS uses similar surveys and research protocols, standardized questionnaire, similar interviewer training, supervision, and implementation in all the countries. For full details of the sampling methodologies, please visit dhsprogram.com.

\section{Dependent variable}

The outcome variable in this study is the recent experience of diarrhoea. Diarrhoea is defined as "passage of liquid stools three or more times a day" $[4,5]$ and "recent experience of diarrhoea" as having any symptom of diarrhoea within two weeks before the interview date [23]. The mothers were asked if any of their U5C had diarrhoea within two weeks preceding the survey. The responses were binary: Yes or No.

\section{Main determinant variable}

The main determinate variable in this decomposition study is the rural-non-rural differentials in the location of the residence of the mothers. The DHS data have already classified study clusters into either rural or nonrural areas using similar standard classification procedures as of the time of the surveys with minimal differences in what rural areas were across the countries. We named children born to rural and non-rural women as rural and non-rural children respectively.

\section{Independent variables}

The identified variables in the literature [5, 20, 24-28] and the Moseley's systematic conceptual framework on study of child survival in developing countries was used to select the explanatory variables in this study [29]. The independent variables used in the study were based on the identified factors associated with diarrhoea among U5C in the literature [5, 20, 24-28]. These are made up of the individual-level and neighbourhood-level factors.

\section{Individual-level factors}

The individual-level consists of childs' characteristics, mothers' characteristics and the households' characteristics. Childs' characteristics: sex (male versus female), age in years (under 1 year and 12-59 months), weight at birth (average+, small and very small), birth interval (firstborn, < 36 months and $>36$ months) and birth order (1, 2, 3 and 4+). Mothers' characteristics: maternal education (none, primary or secondary plus), maternal age (15 to 24,25 to 34,35 to 49 ), marital status (never, currently and formerly married), employment status (working or not working). Households' characteristics: access to media (at least one of radio, television or newspaper), sources of drinking water (improved or unimproved), toilet type (improved or unimproved), cooking fuel (clean fuel or biomass), housing materials (improved or unimproved) and household wealth index (poorest, poorer, middle, richer and richest).

\section{Neighbourhood-level factors}

The DHS uses "clusters" as the PSU as people of the same cluster shares similar contextual factors [21, 22]. We used the word "neighbourhood" to describe the clustering of the children within the same cluster and "neighbours" as members of the same cluster. The PSUs were identified using the most recent census in each country where DHS held. In this study, we considered neighbourhood socioeconomic status (SES) as a community-level variable. It was computed using principal component factor comprised of the proportion of respondents within the same neighbourhood without education, belonging to a household in poor wealth quintiles and unemployed.

\section{Statistical analyses}

We used both descriptive and inferential statistics in this study. Descriptive statistics such as chats, tables, percentages were used to show the distribution of respondents by country, outcome variable and other key variables. Bivariable analysis was conducted to using the Z-test for equality of proportions who had diarrhoea among rural and non-rural children within each country and region (Table 1 (a) and (b)). We also determined the existence of an association between the explanatory variables and the outcome variable among the rural and non-rural groups of children (Table 2(a) and (b)). We carried out country-level comparison of the prevalence of diarrhoea in each of the countries by computing the risk difference (RD) in the development of diarrhoea between U5C from rural and nonrural settings and presented the results in Fig. 1. An $\mathrm{RD}$ greater than 0 suggests that diarrhoea is more prevalent among rural children (pro-rural inequality). Whereas, a negative $\mathrm{RD}$ indicates that diarrhoea is prevalent among non-rural children (pro-non-rural inequality). We estimated the fixed effects as the weighted country-specific risk differences and the random effect as the overall risk difference irrespective of a child's country of residence. As shown in Fig. 1, forest plot was used to illustrate this distributions. Charts were used to show the distributions of the RDs (Figs. 2 and 3). We conducted tests of heterogeneity to ascertain that the 57 countries are different with regards to the odds ratio of having diarrhoea among the rural and non-rural children using adapted z-test in Stata and carried out a test of homogeneity of ORs among the 20 countries with a significant odds ratio of having diarrhoea to determine if the odds of having diarrhoea in those countries are homogenous. Lastly, the adjusted logistic regression 
Table 1 Description of demographic and health surveys data by countries, rural percentage and diarrhoea prevalence among under-five children in LMIC, 2010-2018

\begin{tabular}{|c|c|c|c|c|c|c|c|}
\hline \multirow[t]{2}{*}{ Country } & \multirow{2}{*}{$\begin{array}{l}\text { Year of } \\
\text { Survey }\end{array}$} & \multirow{2}{*}{$\begin{array}{l}\text { Number of } \\
\text { clusters }\end{array}$} & \multirow{2}{*}{$\begin{array}{l}\text { Number of } \\
\text { Under } 5 \text { Children }\end{array}$} & \multirow{2}{*}{$\begin{array}{l}\text { Weighted } \\
\text { (\%) Rural }\end{array}$} & \multicolumn{3}{|c|}{ Weighted Diarrhoea Prevalence (\%) } \\
\hline & & & & & Overall & ${ }^{\mathrm{a}}$ Rural & ${ }^{\mathrm{b}}$ Non-rural \\
\hline \multicolumn{8}{|l|}{ (a) } \\
\hline All & & 63,378 & 796,150 & 68.0 & $* * 14.2$ & *14.6 & 13.4 \\
\hline Eastern Africa & & 6298 & 102,886 & 79.0 & 16.7 & 17.0 & 15.6 \\
\hline Burundi & 2016 & 554 & 12,431 & 90.8 & 22.5 & 23.0 & $* 18.1$ \\
\hline Comoros & 2012 & 252 & 2949 & 72.5 & 17.0 & 17.2 & 16.3 \\
\hline Ethiopia & 2016 & 643 & 9916 & 88.8 & 11.9 & 12.0 & 11.0 \\
\hline Kenya & 2014 & 1593 & 19,889 & 64.4 & 15.4 & 15.8 & *14.5 \\
\hline Malawi & 2016 & 850 & 16,246 & 86.8 & 21.9 & 21.3 & *26.1 \\
\hline Mozambique & 2011 & 610 & 10,157 & 72.4 & 11.2 & 10.8 & *12.4 \\
\hline Rwanda & 2014 & 492 & 7474 & 83.3 & 12.2 & 12.7 & ${ }^{*} 10.0$ \\
\hline Tanzania & 2015 & 608 & 9445 & 73.5 & 12.1 & 11.2 & *14.5 \\
\hline Uganda & 2016 & 696 & 14,379 & 78.8 & 20.0 & 20.7 & $* 17.5$ \\
\hline Middle Africa & & 3081 & 71,630 & 57.7 & 19.0 & 19.2 & 18.8 \\
\hline Angola & 2016 & 625 & 13,463 & 39.1 & 15.7 & 14.9 & *16.3 \\
\hline Cameroon & 2011 & 578 & 10,326 & 56.9 & 21.7 & 24.2 & *18.4 \\
\hline Chad & 2015 & 624 & 16,710 & 80.6 & 22.3 & 22.0 & 23.2 \\
\hline Congo & 2012 & 384 & 8723 & 39.5 & 19.3 & 15.2 & $* 22.0$ \\
\hline Congo DR & 2014 & 536 & 16,994 & 69.1 & 17.0 & 16.2 & *18.8 \\
\hline Gabon & 2012 & 334 & 5414 & 15.4 & 16.8 & 18.4 & 16.5 \\
\hline Northern Africa & & 874 & 15,458 & 68.9 & 14.0 & 14.9 & 12.2 \\
\hline Egypt & 2014 & 874 & 15,458 & 68.9 & 14.0 & 14.9 & $* 12.2$ \\
\hline Southern Africa & & 2544 & 25,529 & 60.7 & 15.5 & 16.3 & *14.3 \\
\hline Lesotho & 2014 & 396 & 2824 & 72.0 & 12.2 & 12.8 & 10.8 \\
\hline Namibia & 2013 & 536 & 4449 & 52.2 & 19.1 & 21.5 & *16.4 \\
\hline South Africa & 2016 & 668 & 3241 & 36.7 & 11.0 & 13.2 & ${ }^{*} 9.7$ \\
\hline Zambia & 2018 & 545 & 9311 & 64.8 & 15.5 & 15.6 & 15.3 \\
\hline Zimbabwe & 2015 & 399 & 5704 & 68.2 & 17.1 & 17.1 & 17.0 \\
\hline West Africa & & 6285 & 139,382 & 67.3 & 14.7 & 15.3 & *13.4 \\
\hline Benin & 2018 & 555 & 12,512 & 61.0 & 10.5 & 11.1 & *9.6 \\
\hline Burkina Faso & 2010 & 573 & 13,621 & 82.7 & 14.9 & 14.5 & *16.4 \\
\hline Cote d'Ivoire & 2012 & 351 & 6876 & 62.4 & 18.5 & 18.0 & 19.2 \\
\hline Gambia & 2013 & 281 & 7633 & 52.7 & 17.8 & 16.7 & *18.9 \\
\hline Ghana & 2014 & 427 & 5539 & 55.0 & 11.9 & 12.9 & *10.6 \\
\hline Guinea & 2015 & 401 & 7213 & 70.4 & 14.6 & 14.6 & 14.6 \\
\hline Liberia & 2013 & 322 & 6806 & 50.1 & 22.7 & 24.7 & *20.7 \\
\hline Mali & 2018 & 345 & 9171 & 79.3 & 17.2 & 17.9 & *14.7 \\
\hline Niger & 2012 & 476 & 11,437 & 86.3 & 14.4 & 14.1 & *16.2 \\
\hline Nigeria & 2018 & 1389 & 30,603 & 60.5 & 12.8 & 14.9 & *9.6 \\
\hline Senegal & 2017 & 400 & 11,253 & 63.1 & 18.0 & 19.3 & *15.8 \\
\hline Sierra Leone & 2013 & 435 & 10,254 & 74.9 & 11.5 & 11.3 & 12.3 \\
\hline Togo & 2013 & 330 & 6464 & 63.9 & 15.2 & 17.7 & *10.8 \\
\hline Central Asia & & 682 & 10,216 & 75.5 & 10.2 & 10.7 & *8.5 \\
\hline
\end{tabular}


Table 1 Description of demographic and health surveys data by countries, rural percentage and diarrhoea prevalence among under-five children in LMIC, 2010-2018 (Continued)

\begin{tabular}{|c|c|c|c|c|c|c|c|}
\hline \multirow[t]{2}{*}{ Country } & \multirow{2}{*}{$\begin{array}{l}\text { Year of } \\
\text { Survey }\end{array}$} & \multirow{2}{*}{$\begin{array}{l}\text { Number of } \\
\text { clusters }\end{array}$} & \multirow{2}{*}{$\begin{array}{l}\text { Number of } \\
\text { Under } 5 \text { Children }\end{array}$} & \multirow{2}{*}{$\begin{array}{l}\text { Weighted } \\
\text { (\%) Rural }\end{array}$} & \multicolumn{3}{|c|}{ Weighted Diarrhoea Prevalence (\%) } \\
\hline & & & & & Overall & ${ }^{\text {a} R u r a l ~}$ & ${ }^{b}$ Non-rura \\
\hline Kyrgyz Rep & 2012 & 316 & 4222 & 70.2 & 5.2 & 5.8 & *3.8 \\
\hline Tajikistan & 2017 & 366 & 5994 & 78.9 & 13.3 & 13.4 & 12.7 \\
\hline South-Eastern Asia & & 1850 & 17,168 & 68.3 & 9.0 & 9.8 & $* 7.2$ \\
\hline Cambodia & 2014 & 609 & 6934 & 85.5 & 12.9 & 12.9 & 12.8 \\
\hline Philippines & 2017 & 1241 & 10,234 & 55.8 & 6.1 & 6.3 & 5.8 \\
\hline (b) & & & & & & & \\
\hline All & & 63,378 & 796,150 & 68.0 & $* * 14.2$ & *14.6 & 13.4 \\
\hline Southern Asia & & 33,053 & 322,219 & 70.5 & 11.5 & 11.9 & ${ }^{*} 10.8$ \\
\hline Afghanistan & 2015 & 956 & 30,520 & 76.7 & 29.1 & 28.1 & *32.4 \\
\hline Bangladesh & 2014 & 600 & 7541 & 74.4 & 5.7 & 5.7 & 5.7 \\
\hline India & 2016 & 28,321 & 247,181 & 71.6 & 9.2 & 9.6 & $* 8.2$ \\
\hline Indonesia & 2017 & 1967 & 17,155 & 51.5 & 14.2 & 15.4 & *12.9 \\
\hline Maldives & 2016 & 265 & 3048 & 64.8 & 4.2 & 4.4 & 4.0 \\
\hline Nepal & 2016 & 383 & 4827 & 45.9 & 7.7 & 7.4 & 7.9 \\
\hline Pakistan & 2018 & 561 & 11,947 & 67.6 & 19.2 & 19.2 & 19.2 \\
\hline Western Asia & & 2048 & 27,441 & 48.8 & 21.8 & 29.1 & $* 14.9$ \\
\hline Armenia & 2016 & 306 & 1709 & 42.3 & 3.8 & 5.4 & $* 2.7$ \\
\hline Jordan & 2017 & 962 & 10,454 & 11.5 & 9.7 & 9.8 & 9.6 \\
\hline Yemen & 2013 & 780 & 15,278 & 72.8 & 31.4 & 32.6 & *28.3 \\
\hline Central America & & 1996 & 22,524 & 59.5 & 18.7 & 19.3 & $* 17.8$ \\
\hline Guatemala & 2014 & 856 & 12,038 & 64.1 & 19.2 & 19.3 & 19.1 \\
\hline Honduras & 2011 & 1140 & 10,486 & 53.8 & 18.0 & 19.1 & *16.6 \\
\hline South America & & 1401 & 9408 & 34.3 & 12.3 & 12.8 & 12.1 \\
\hline Peru & 2012 & 1401 & 9408 & 34.3 & 12.3 & 12.8 & 12.1 \\
\hline Southern Europe & & 651 & 2745 & 43.8 & 6.1 & 8.2 & $* 4.4$ \\
\hline Albania & 2018 & 651 & 2745 & 43.8 & 6.1 & 8.2 & $* 4.4$ \\
\hline Caribbean & & 1860 & 21,129 & 62.8 & 15.0 & 13.6 & $* 17.4$ \\
\hline Dominican Rep & 2013 & 516 & 3560 & 25.5 & 18.2 & 17.5 & 18.4 \\
\hline Haiti & 2016 & 449 & 6082 & 64.9 & 21.4 & 20.6 & *22.8 \\
\hline Myanmar & 2014 & 440 & 4575 & 77.5 & 10.5 & 11.1 & *8.4 \\
\hline Timor-Leste & 2016 & 455 & 6912 & 71.1 & 10.8 & 9.1 & $* 14.8$ \\
\hline Oceania & & 755 & 8415 & 89.2 & 15.4 & 14.5 & $* 23.2$ \\
\hline Papua New Guinea & 2016 & 755 & 8415 & 89.2 & 15.4 & 14.5 & $* 23.2$ \\
\hline
\end{tabular}

**significant at $5 \%$ Chi-square test, ${ }^{*}$ significant at $5 \%$ test of equality of proportions a and b

method was applied to the pooled cross-sectional data from the 57 LMIC to carry out a Fairlie decomposition analysis (FDA) and the results presented in Fig. 4.

\section{Decomposition analysis}

We applied Fairlie Multivariable decomposition based on the binary regression model. It belongs to the family of decomposition techniques used to quantify the contributions to differences in the prediction of an outcome of interest between two groups in multivariate models [30]. It is an extension of the Blinder-Oaxaca Decomposition Analysis (BODA) [31-33]. While the BODA works best for continuous outcomes Fairlie is renowned for the logit and probit model [34-38]. Fairlie et al. noted that the nonlinear decomposition techniques helped to overcome the 
Table 2 Summary of pooled sample characteristics of the studied children in 57 LMIC

\begin{tabular}{|c|c|c|c|c|c|c|}
\hline \multirow[t]{2}{*}{ Characteristics } & \multirow[t]{2}{*}{$\mathbf{N}$} & \multirow{2}{*}{$\begin{array}{l}\text { Weighted } \\
\%\end{array}$} & \multirow{2}{*}{$\begin{array}{l}\text { Weighted } \\
\text { (\%) Rural }\end{array}$} & \multicolumn{3}{|c|}{ Weighted Diarrhoea Prevalence (\%) } \\
\hline & & & & Overall & Rural & Non-rural \\
\hline \multicolumn{7}{|l|}{ (a) } \\
\hline \multicolumn{7}{|l|}{ Age } \\
\hline Infant & 164,438 & 20.7 & 68.5 & *17.4 & *18.0 & *16.1 \\
\hline $12-59$ months & 631,712 & 79.4 & 67.9 & 13.4 & 13.7 & 12.7 \\
\hline \multicolumn{7}{|l|}{ Sex } \\
\hline Female & 389,173 & 48.9 & 68.2 & *13.8 & *14.1 & $* 13.1$ \\
\hline Male & 406,977 & 51.1 & 67.9 & 14.6 & 15.1 & 13.7 \\
\hline \multicolumn{7}{|l|}{ Household Head } \\
\hline Male & 669,287 & 84.1 & 68.8 & *14.2 & 14.6 & $* 13.2$ \\
\hline Female & 126,863 & 15.9 & 64.1 & 14.5 & 14.7 & 14.2 \\
\hline \multicolumn{7}{|l|}{ Maternal age } \\
\hline $15-24$ years & 234,550 & 29.5 & 70.7 & *16.4 & *16.3 & $* 16.5$ \\
\hline $25-34$ years & 414,014 & 52.0 & 66.3 & 13.2 & 13.7 & 12.3 \\
\hline $35-49$ years & 147,586 & 18.5 & 68.7 & 13.4 & 14.1 & 12.0 \\
\hline \multicolumn{7}{|l|}{ Maternal Education } \\
\hline No education & 273,056 & 34.3 & 83.2 & *15.8 & *15.7 & *15.9 \\
\hline Primary & 202,835 & 25.5 & 73.9 & 16.3 & 16.3 & 16.3 \\
\hline Secondary or higher & 320,257 & 40.2 & 52.2 & 11.7 & 11.7 & 11.7 \\
\hline \multicolumn{7}{|l|}{ Household Wealth Index } \\
\hline Poorest & 202,853 & 25.5 & 92.3 & *15.1 & *15.2 & *13.8 \\
\hline Poorer & 178,258 & 22.4 & 86.7 & 14.8 & 14.9 & 13.9 \\
\hline Middle & 158,228 & 19.9 & 74.2 & 14.2 & 14.4 & 13.7 \\
\hline Richer & 139,713 & 17.6 & 50.7 & 13.9 & 14.0 & 13.8 \\
\hline Richest & 117,098 & 14.7 & 21.3 & 12.5 & 11.5 & 12.8 \\
\hline \multicolumn{7}{|l|}{ Employment } \\
\hline Employed & 526,983 & 66.2 & 69.4 & *13.3 & *13.7 & $*^{*} 12.3$ \\
\hline Unemployed & 269,167 & 33.8 & 65.4 & 16.0 & 16.4 & 15.3 \\
\hline \multicolumn{7}{|l|}{ Media access } \\
\hline No & 316,993 & 39.9 & 85.0 & *15.2 & *15.3 & *14.8 \\
\hline Yes & 478,517 & 60.2 & 57.6 & 14.2 & 14.0 & 13.1 \\
\hline \multicolumn{7}{|l|}{ Drinking water sources } \\
\hline Unimproved sources & 175,663 & 22.8 & 87.0 & *16.9 & *16.8 & $* 17.3$ \\
\hline Improved sources & 595,332 & 77.2 & 63.1 & 13.6 & 13.9 & 13.1 \\
\hline \multicolumn{7}{|l|}{ Toilet type } \\
\hline Unimproved sources & 388,386 & 50.4 & 85.3 & *15.4 & *15.3 & *15.9 \\
\hline Improved sources & 382,305 & 49.6 & 51.2 & 13.1 & 13.5 & 12.7 \\
\hline \multicolumn{7}{|l|}{ Marital status } \\
\hline Never married & 23,560 & 3.0 & 50.8 & *16.9 & $* 17.8$ & *15.9 \\
\hline Currently married & 739,740 & 92.9 & 68.9 & 14.0 & 14.4 & 23.1 \\
\hline Formerly married & 32,850 & 4.1 & 61.1 & 17.1 & 17.1 & 17.0 \\
\hline \multicolumn{7}{|l|}{ Cooking Fuel } \\
\hline Unclean/Biomass & 581,710 & 77.0 & 80.1 & ${ }^{*} 14.9$ & *14.8 & *15.1 \\
\hline Clean Fuel & 173,921 & 23.0 & 33.3 & 12.4 & 13.3 & *11.9 \\
\hline
\end{tabular}


Table 2 Summary of pooled sample characteristics of the studied children in 57 LMIC (Continued)

\begin{tabular}{|c|c|c|c|c|c|c|}
\hline \multirow[t]{2}{*}{ Characteristics } & \multirow[t]{2}{*}{$\mathbf{N}$} & \multirow{2}{*}{$\begin{array}{l}\text { Weighted } \\
\%\end{array}$} & \multirow{2}{*}{$\begin{array}{l}\text { Weighted } \\
\text { (\%) Rural }\end{array}$} & \multicolumn{3}{|c|}{ Weighted Diarrhoea Prevalence (\%) } \\
\hline & & & & Overall & Rural & Non-rural \\
\hline \multicolumn{7}{|l|}{ Housing materials } \\
\hline Unimproved sources & 676,227 & 89.5 & 70.9 & ${ }^{*} 14.8$ & *15.1 & *14.3 \\
\hline Improved source & 79,157 & 10.5 & 47.2 & 10.0 & 10.1 & 9.9 \\
\hline \multicolumn{7}{|l|}{ Weight at birth } \\
\hline Average+ & 643,472 & 84.0 & 67.4 & *13.6 & *14.0 & *12.8 \\
\hline Small & 90,809 & 11.9 & 70.0 & 17.2 & 17.7 & 16.0 \\
\hline Very small & 31,924 & 4.2 & 70.9 & 20.1 & 20.3 & 19.5 \\
\hline Total & 796,150 & 100.0 & 68.0 & 14.2 & 14.6 & 13.4 \\
\hline \multicolumn{7}{|l|}{ (b) } \\
\hline \multicolumn{7}{|l|}{ Birth Interval } \\
\hline 1st Birth & 223,779 & 28.2 & 63.0 & $* 13.1$ & *13.5 & $* 12.5$ \\
\hline$<36$ months & 308,310 & 38.8 & 73.5 & 15.0 & 15.2 & 14.4 \\
\hline $36+$ months & 262,278 & 33.0 & 66.2 & 14.3 & 14.7 & 13.4 \\
\hline \multicolumn{7}{|l|}{ Birth Order } \\
\hline $1 s t$ & 223,777 & 28.1 & 63.0 & $* 13.1$ & *13.5 & *12.5 \\
\hline 2nd & 192,088 & 24.1 & 64.5 & 13.1 & 13.4 & 12.5 \\
\hline $3 r d$ & 129,829 & 16.3 & 67.8 & 14.2 & 14.4 & 13.7 \\
\hline $4+$ & 250,456 & 31.5 & 75.9 & 16.2 & *16.3 & 15.6 \\
\hline \multicolumn{7}{|l|}{ Neighbourhood SES } \\
\hline Highest & 159,709 & 20.1 & 37.6 & *9.8 & *8.8 & $* 10.4$ \\
\hline 2 & 158,969 & 20.0 & 22.6 & 14.9 & 12.9 & 15.5 \\
\hline 3 & 160,077 & 20.1 & 87.4 & 15.8 & 15.8 & 15.6 \\
\hline 4 & 159,153 & 20.0 & 98.1 & 16.7 & 16.7 & 16.2 \\
\hline Lowest & 158,242 & 19.9 & 98.2 & 14.0 & 14.1 & 9.9 \\
\hline Total & 796,150 & 100.0 & 68.0 & 14.2 & 14.6 & 13.4 \\
\hline
\end{tabular}

${ }^{*}$ significant at 5\% Chi-square test

challenges of the BODA when group differences are large for an independent variable [35]. We used the Fairlie methods in this study as it was purposively developed for non-linear regression models including the logit and probit models [38].

The Fairlie works by decomposing the difference in proportions based on either the probit or logit models into the portion of the characteristic [30]. The decomposition analysis was carried out by calculating the difference between the predicted probability for one group (say Group A) using the other group's (say Group B) regression coefficients and the predicted probability for that group (Group A) using its regression coefficients [35]. The Fairlie decomposition technique works by constraining the predicted probability between 0 and 1 .

Fairlie et al. showed that the decomposition for a nonlinear equation $Y=F(X)$, can be expressed as:

$$
\overline{\mathrm{Y}}^{A}-\overline{\mathrm{Y}}^{B}=\overbrace{\left[\sum_{[=1}^{N^{A}} \frac{F\left(X_{i}^{A} \hat{\beta}^{A}\right)}{N^{A}}-\sum_{i=1}^{N^{B}} \frac{F\left(X_{i}^{B} \hat{\beta}^{A}\right)}{N^{B}}\right]}^{\mathrm{st}^{t}}+\overbrace{\left[\sum_{i=1}^{N^{B}} \frac{F\left(X_{i}^{B} \hat{\beta}^{A}\right)}{N^{B}}-\sum_{i=1}^{N^{B}} \frac{F\left(X_{i}^{B} \hat{\beta}^{B}\right)}{N^{B}}\right]}^{2^{n d}}
$$

Where $N^{A}$ is the sample size for group $J$ [39]. In eq. (1), $\bar{Y}$ is not necessarily the same as $F(\bar{X} \hat{\beta})$, unlike in BODA where $F\left(X_{i} \beta\right)=X_{i} \beta$. The 1st term is the part of the gap in the binary outcome variable that is due to group differences in distributions of $X$, and the 2nd term is the part due to differences in the group processes determining levels of $Y$. The 2nd term also captures the portion of the binary outcome variable gap due to group differences in unmeasurable or unobserved endowments.

The estimation of the total contribution is the difference between the average values of the predicted probabilities. Using coefficient estimates from a logit regression model 




Fig. 1 Prevalence and risk difference of diarrhoea between rural and non-rural children by countries

for a pooled sample, $\hat{\beta}^{*}$, the independent contribution of $X_{1}$ and $X_{2}$ to the group, gap can be written as

$$
\frac{1}{N^{B}} X \sum_{i=1}^{N^{B}} F\left(\hat{\alpha}^{*}+X_{1 i}^{A} \hat{\beta}_{1}^{*}+X_{2 i}^{A} \hat{\beta}_{2}^{*}\right)-F\left(\hat{\alpha}^{*}+X_{1 i}^{B} \hat{\beta}_{1}^{*}+X_{2 i}^{A} \hat{\beta}_{2}^{*}\right)
$$

and

$$
\frac{1}{N^{B}} X \sum_{i=1}^{N^{B}} F\left(\hat{\alpha}^{*}+X_{1 i}^{B} \hat{\beta}_{1}^{*}+X_{2 i}^{A} \hat{\beta}_{2}^{*}\right)-F\left(\hat{\alpha}^{*}+X_{1 i}^{B} \hat{\beta}_{1}^{*}+X_{2 i}^{B} \hat{\beta}_{2}^{*}\right)
$$

respectively. The contribution of each variable to the gap is thus equal to the change in the average predicted probability from replacing the group $B$ distribution with the group $A$ distribution of that variable while holding the distributions of the other variable constant. To obtain an accurate decomposition estimate, Fairlie et al. recommended the replication of the decomposition from a minimum of 1000 subsamples and finding the mean values of estimates from each separate decomposition [35]. Further numerical details have been reported [35, $36,38-40]$. Respectively, the contribution of each variable to the gap is thus equal to the change in the average predicted probability from replacing the group $B$ distribution with the group $A$ distribution of that variable while holding the distributions of the other variable constant. To obtain an accurate decomposition estimates, 


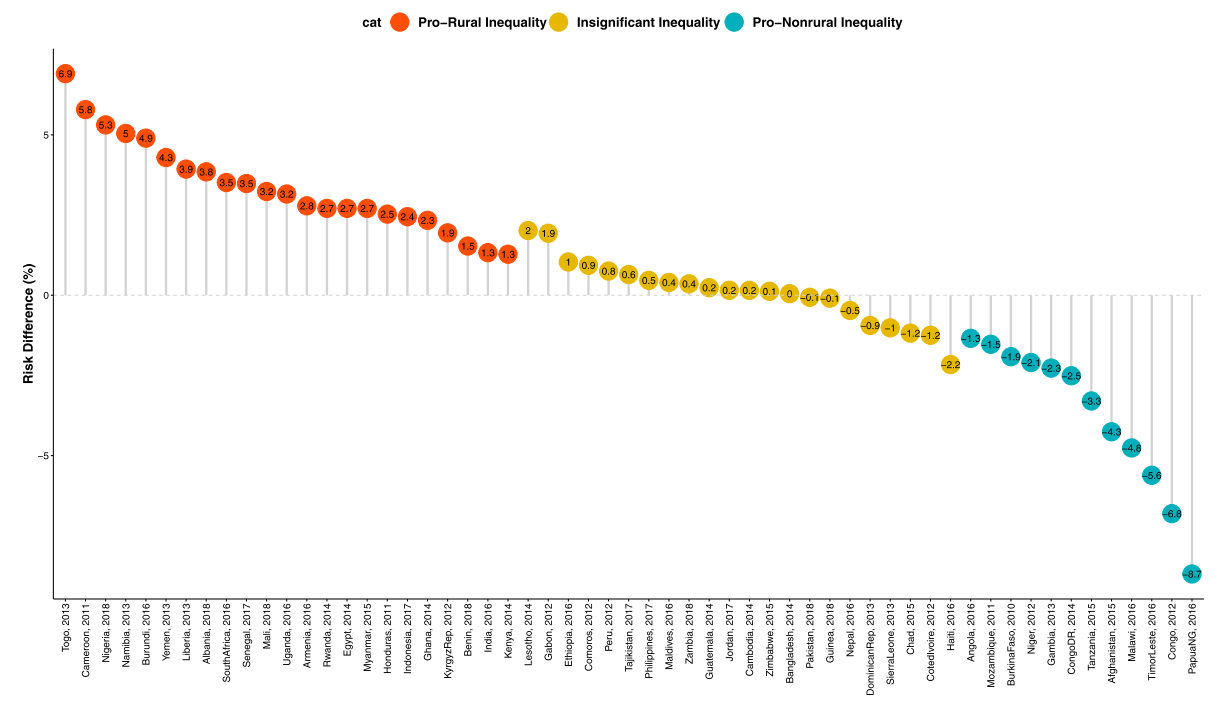

Fig. 2 Risk difference between rural and non-rural children in the prevalence of diarrhoea by countries

Fairlie et al. recommended the replication of the decomposition from a minimum of 1000 subsamples and finding the mean values of estimates from each separate decomposition [35]. Further numerical details have been reported [35, 36, 38-40].

We used the "Fairlie" command in STATA 16 (StataCorp, College Station, Texas, United States of America) to carry out the decomposition analysis to enable the quantification of how much of the gap between the "advantaged" (non-rural) and the "disadvantaged" (rural) groups is attributable to differences in specific measurable characteristics. Using the generalised structure of the model, we fitted a logistic model to determine factors influencing diarrhoea occurrence among rural and non-rural children.

\section{Results}

\section{Sample characteristics and analysis of inequality}

The percentage of children from rural areas was $68.0 \%$, least $(11.5 \%)$ in Jordan and the highest $(90.8 \%)$ in Burundi. The overall weighted prevalence of diarrhoea was 14.2, $14.6 \%$ vs $13.4 \%$ among rural and non-rural children respectively $(p<0.001)$. The prevalence of diarrhoea among rural children ranged from $4.4 \%$ in the Maldives to $32.6 \%$ in Yemen, while it ranged from $2.7 \%$ in Armenia to $32.4 \%$ in Afghanistan among non-rural children. The z-test of

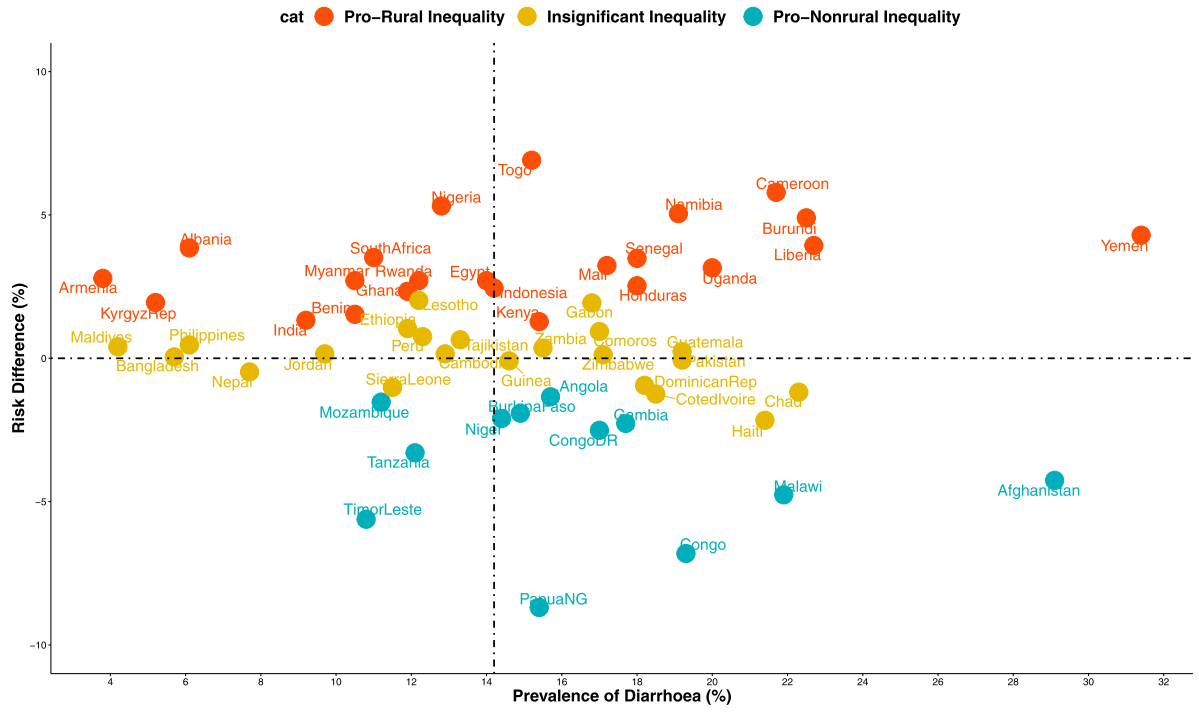

Fig. 3 Scatter plot of prevalence and risk difference of diarrhoea between rural and non-rural children in LMIC 


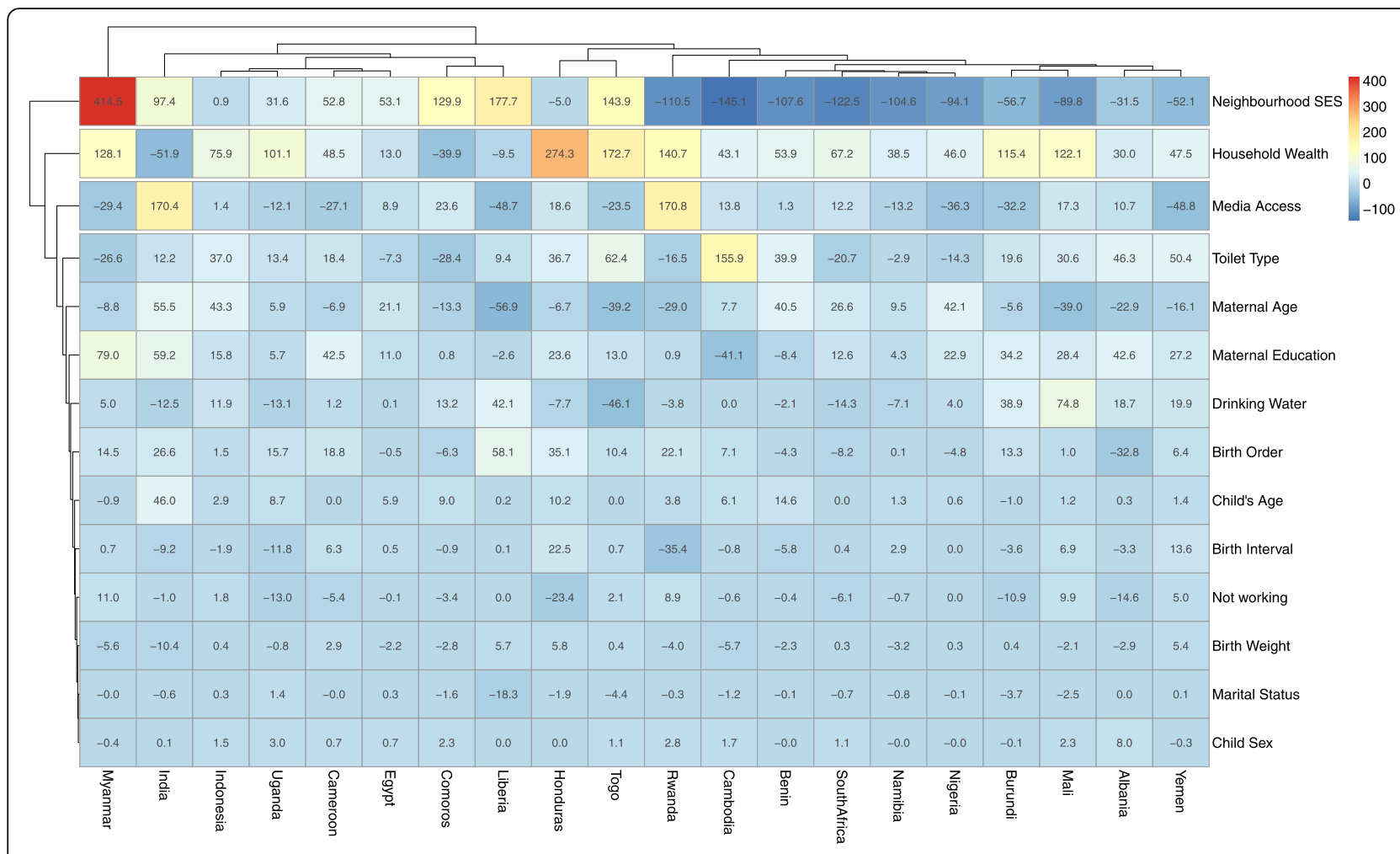

Fig. 4 Contributions of differences in the distribution of 'compositional effect' of the determinants of having diarrhoea to the total gap between rural and non-rural children by countries

equality of prevalence among the rural and non-rural children was statistically significant $(p<0.05)$ in Afghanistan $(p<0.001)$, Albania $(p<0.001)$, Angola $(p<0.001)$, Armenia $(p<0.001)$, Benin $(p<0.001)$, Burkina Faso $(p<0.001)$, Burundi $(p<0.001)$, Cameroon $(p<0.001)$, Congo $(p<$ $0.001)$, Congo DR $(p<0.001)$, Egypt $(p<0.001)$, Gambia $(p<0.001)$, Ghana $(p<0.001)$, Haiti $(p<0.001)$, Honduras $(p<0.001)$, India $(p<0.001)$, Indonesia $(p<0.001)$, Kyrgyz Rep $(p<0.001)$, Liberia $(p<0.001)$, Malawi $(p<0.001)$, Mali $(p<0.001)$, Myanmar $(p<0.001)$, Mozambique $(p<0.001)$, Namibia $(p<0.001)$, Niger $(p<0.001)$, Nigeria $(p<0.001)$, Papua New Guinea $(p<0.001)$, Pakistan $(p<0.001)$, Rwanda $(p<0.001)$, Senegal $(p<0.001)$, South Africa $(p<$ $0.001)$, Tanzania $(p<0.001)$, Timor-Leste $(p<0.001)$, Togo $(p<0.001)$, Uganda $(p<0.001)$, Yemen $(p<0.001)$ as shown in Table 1(a) and (b).

As shown in Table 2(a) and (b), all the explanatory variables considered were significantly associated $(p<$ 0.05 ) with the occurrence of diarrhoea among all the children and by rural-non-rural location of residence except the sex of household head that was insignificantly associated with the occurrence of diarrhoea $(p=0.058)$ among rural children. The prevalence of diarrhoea was consistently higher among infants compared with those aged $12-59$ months both in the rural area (18\% vs $14 \%)$ and in the non-rural areas (16\% vs $13 \%)$.

\section{Diarrhoea among rural and non-rural under-five children}

The risk differences, a measure of inequality, in the risk of having diarrhoea among children of women from rural and non-rural areas across the countries studied are presented in Figs. 1, 2 and 3. Also, the prevalence of diarrhoea among both the rural and non-rural in each of the countries were computed and presented the results in Fig. 1. The prevalence of diarrhoea was generally higher in the rural areas than in the non-rural areas in all the countries except in Afghanistan, Angola, Burkina Faso, Chad, Congo, Congo DR, Cote d'Ivoire, Dominican Rep, Gambia, Haiti, Malawi, Mozambique, Nepal, Niger, Papua New Guinea, Sierra Leone, Tanzania, and TimorLeste.

The pro-rural differences in diarrhoea were widest in Burundi (48.99/1000 children) and pro-non-rural RD was widest for Malawi $(-47.63 / 1000)$ in Eastern Africa. In Middle Africa, the largest pro-rural difference was in Cameroon (57.89/1000) and pro-non-rural RD was highest for Congo $(-68.11 / 1000)$. In The Caribbean, the prorural difference was widest in Myanmar (27.07/1000) and the pro-non-rural difference was widest in Timor Leste $(-56.14)$. Irrespective of regions, the fixed effects of pro-rural differences was widest in Togo (69.09/1000) while the fixed effects of pro-non-rural differences were widest in Papua New Guinea (86.92/1000). Overall, the 
random effects, of the risk difference per 1000 children was $6.22 / 1000$ children with a $95 \%$ confidence interval (CI): -0.50-12.93), evidence of insignificant overall prorural inequality. The greatest contribution (weight) to the random effect was found in Nigeria and India at 2\% each while the least was in Comoros and Gabon at 1.4\% each (Fig. 1).

In Figs. 2 and 3, we used the colours red, orange and to indicate statistically significant pro-rural inequality, insignificant inequality and statistically significant pronon-rural inequality respectively. Based on risk differences, four of the nine countries in Eastern Africa, one of the countries in Middle Africa, Egypt in Northern Africa, two in Southern Africa and seven countries in West Africa showed statistically significant pro-rural inequality. Two countries each in Western and Southern Asia, one country each in Central Asia, Central America and Southern Europe and none in South America and Oceania had statistically significant pro-rural inequality in children having diarrhoea (Figs. 1, 2 and 3).

\section{Relationship between prevalence of diarrhoea and magnitude of inequality}

The relationships between the prevalence of diarrhoea and the magnitude of rural-non-rural inequality, a function of $\mathrm{RD}$, across the 57 countries considered in this study are presented in Fig. 3. We categorised the countries into four distinct categories based on their prevalence of diarrhoea and whether or not the differences were small or large: (i) High diarrhoea and high prorural inequality countries such as Togo, Yemen, Cameroun, Burundi and Namibia (ii) High diarrhoea and high pro-non-rural inequality countries such as Afghanistan, Congo, Malawi, and Papua New Guinea (iii) Low diarrhoea and high pro-rural inequality countries such as Nigeria, Egypt, South Africa and Egypt (iv) Low diarrhoea and high pro-non-rural inequality countries such as Timor Leste, Tanzania, and Mozambique.

\section{Decomposition of rural-non-rural inequality in the prevalence of diarrhoea}

We first computed Mantel-Haenszel pooled estimate of the odds ratio (OR) of having diarrhoea while controlling for the countries among all the children. We estimated $\mathrm{OR}=1.06$ (95\% CI: $1.04-1.07)$ and tested if the $\mathrm{OR}=1$ using $\mathrm{z}$-test; and obtained $\mathrm{z}=7.45$ and $p=0.000$ and (ii) Test of heterogeneity: $X^{2}=650.04$, degree of freedom (d.f.) $=56$, and $\mathrm{p}=0.000$, I-squared (variation in odds ratio (OR) attributable to heterogeneity) $=91.4 \%$. Of the 57 countries, statistically significant pro-rural odds ratio (pro-rural inequality) was recorded in only 20 countries. The countries are Albania $(\mathrm{OR}=1.769 ; p=$ $0.001)$, Benin $(\mathrm{OR}=1.209 ; p=0.002)$, Burundi $(\mathrm{OR}=$ $1.399 ; p<0.001)$, Cambodia $(\mathrm{OR}=1.201 ; p<0.031)$,
Cameroon $(\mathrm{OR}=1.377 ; p<0.001)$, Comoros $(\mathrm{OR}=$ $1.266 ; \quad p=0.029), \quad$ Egypt $(\mathrm{OR}=1.331 ; p<0.001)$, Honduras (OR $=1.127 ; p=0.027)$, India $(\mathrm{OR}=1.059 ; p<$ $0.001)$, Indonesia $(\mathrm{OR}=1.219 ; p<0.001)$, Liberia $(\mathrm{OR}=$ $1.158 ; p=0.017)$, Mali $(\mathrm{OR}=1.240 ; p=0.001)$, Myanmar $(\mathrm{OR}=1.422 ; p=0.004)$, Namibia $(\mathrm{OR}=1.451 ; p<0.001)$, Nigeria $(\mathrm{OR}=1.492 ; p<0.001)$, Rwanda $(\mathrm{OR}=1.261 ; p=$ $0.010)$, South Africa ( $\mathrm{OR}=1.420 ; p=0.002)$, Togo $(\mathrm{OR}=$ $1.729 ; p<0.001)$, Uganda ( $\mathrm{OR}=1.214 ; p<0.001)$, and Yemen $(\mathrm{OR}=1.249 ; p<0.001)$. All the 20 countries have statistically significant odd ratios with $95 \%$ confidence interval higher than 1 and $p$-values less than $5 \%$ alpha level as shown in Table 3. Whereas, pro-non-rural inequalities were evident in nine countries while the remaining countries experienced insignificant inequalities.

For the purpose of confirmation that the 20 countries were homogeneous as far as significant higher odds of diarrhoea among rural children than among nonrural children is concerned, we computed Mantel-Haenszel pooled estimate of the odds ratio (OR) of having diarrhoea among the children in the 20 countries while controlling for the countries. We had OR $=1.20$ (95\% CI: $1.17-1.23)$ and tested the homogeneity of the ORs: $X^{2}=$ 144.75, degree of freedom (d.f.) $=19$, and $p=0.000$. All the tests were significant.

Table 3 The odds ratio of diarrhoea in pro-rural countries

\begin{tabular}{llll}
\hline Country & Odds Ratio & P-value & $\mathbf{9 5 \% ~ C l}$ \\
\hline Albania & 1.769 & 0.002 & $1.232-2.538$ \\
Benin & 1.209 & 0.002 & $1.075-1.360$ \\
Burundi & 1.399 & 0.000 & $1.235-1.585$ \\
Cambodia & 1.201 & 0.031 & $1.017-1.418$ \\
Cameroon & 1.377 & 0.000 & $1.245-1.523$ \\
Comoros & 1.266 & 0.029 & $1.024-1.565$ \\
Egypt & 1.331 & 0.000 & $1.207-1.469$ \\
Honduras & 1.127 & 0.027 & $1.013-1.253$ \\
India & 1.059 & 0.001 & $1.025-1.094$ \\
Indonesia & 1.219 & 0.000 & $1.119-1.329$ \\
Liberia & 1.158 & 0.017 & $1.026-1.306$ \\
Mali & 1.240 & 0.001 & $1.091-1.409$ \\
Myanmar & 1.422 & 0.004 & $1.121-1.802$ \\
Namibia & 1.451 & 0.000 & $1.240-1.697$ \\
Nigeria & 1.492 & 0.000 & $1.386-1.607$ \\
Rwanda & 1.261 & 0.010 & $1.056-1.506$ \\
South Africa & 1.420 & 0.002 & $1.135-1.775$ \\
Togo & 1.729 & 0.000 & $1.469-2.034$ \\
Uganda & 1.214 & 0.001 & $1.087-1.355$ \\
Yemen & 1.249 & 0.000 & $1.149-1.357$ \\
\hline
\end{tabular}


We included only the 20 LMIC with significantly higher odds of having diarrhoea among the rural children compared with the non-rural children in the Fairlie decomposition analysis. Figures 4 show the detailed decomposition of the part of the pro-rural inequality caused by compositional effects of the determinants of diarrhoea among under-five children by the pro-rural and pro-non-rural inequality countries respectively. The "explained" (compositional component) and the "unexplained" (structural component) portions of the ruralnon-rural inequalities are depicted by red and blue colours respectively in Fig. 4. The lighter the red colour, the lower the percentage contribution of the "explained" portion and the lighter the blue colour, the lower the percentage contribution of the "unexplained" portion. We found wide variations in the factors associated with the pro-rural and pro-non-rural inequalities across the countries.

Generally, neighbourhood SES, household wealth quintile, access to media, toilet types and maternal age and education were the most important factors in most countries. Specifically, the largest contributions to prorural inequality in the prevalence of diarrhoea were neighbourhood SES (414\% higher in communities with lowest SES), followed by household wealth index (128\% higher among children from households in the poorest wealth quintiles), maternal education (79\% higher among parents with no education), media access and toilet types in Myanmar. In India, the greatest contributors to the disparities are media access, neighbourhood SES, maternal education, maternal ages and birth order. The disparities were better explained by household wealth quintiles, toilet type, and maternal age in Yemen whereas the most significant contributors are neighbourhood SES, household wealth quintile, access to media, toilet types and sources of drinking water in Yemen. Other factors such as childbirth weight, age and sex, mothers' employment status, marital status had the lowest contribution to rural-non-rural inequality in the prevalence of diarrhoea across these countries.

\section{Discussion}

In this study, we pooled data from 57 LMIC to assess individual- and neighbourhood-level factors that explain the rural-non-rural inequalities in the development of childhood diarrhoea using the Fairlie Multivariable decomposition analysis. The study was designed on the premise that there are disparities in the health status of children living in rural non-rural areas in LMIC. We found significant disparities across countries in the factors associated with the pro-rural and pro-non-rural inequalities in the occurrence of diarrhoea. The findings in this study show the non-uniform variation in the prevalence of diarrhoea among children whose mothers reside in rural and non-rural communities. This alludes to the importance of residential inequalities in the occurrence of diarrhoea. The significant residential-related differences could be attributed to the individual characteristics across countries.

Similar to outcomes of the previous study, a higher prevalence of diarrhoea was found in the rural area as compared to non-rural areas of study. The pro-rural inequality found mostly in Asian countries as reported in the previous study [1] could be a result of a lack of social amenities and basic infrastructure needed in the rural area. In the non-rural settings, Southern and Western Asia shared the least and most burden of diarrhoea risk difference as reported in another study [41].

The study also identified factors associated with the occurrence of diarrhoea in LMIC. All the examined factors except sex of household head significantly predict the development of diarrhoea among U5C. Notably, in both rural and non-rural settings, the infants are said to be more predisposed to diarrhoea as found in the previous studies [17, 42,43] which is said to be more pronounced among the female children though this is contrary to some studies $[44,45]$. Furthermore, the age of the mother is found to be significantly associated with the development of diarrhoea as children from young mothers age 15-24 are largely exposed. This could be because at this age many of the mothers are still teenagers and some might not have the financial capability and knowledge of raising a healthy child as supported in a previous study [46]. This study also revealed that children born to non-educated mothers are susceptible to diarrhoea. Educated mothers are more likely to have adequate knowledge on the importance of good hygiene as compared to uneducated mothers. This position is supported by Fikire et al. in their study on understanding the determinants of delay in care-seeking for diarrhoea diseases among mothers/caregivers with U5C in public health facilities in Southern Ethiopia [47].

Furthermore, this study shows that unemployment [48], low economic status, and lack of access to media gadget such as television and radio among mothers are associated with the risk of their children developing diarrhoea [49]. As affirmed by other studies, an average weighted child at birth [41] firstborns [46] and children born to parents with low access to infrastructural facilities such as improved toilet [50] and improved housing materials have a higher risk of diarrhoea occurrence. Access to improved toilet facilities allows for safer disposal of faeces and limit the risk of contact between diarrhoea causative organism and human host [2].

Moreover, obvious intercountry differences in the riskdifference in diarrhoea between rural and non-rural areas were recorded. In most of the countries, the prevalence of mortality was of higher proportion in the rural 
areas, with an exception in 20 countries. Based on regions, the largest statistically significant pro-rural inequality in children having diarrhoea was found in Eastern Africa (in Burundi, Uganda, Rwanda and Kenya), Northern Africa (in Egypt), Southern Africa (in Namibia, South Africa). There was no significant pro-rural inequality in South-Eastern Asia and Oceania. Moreover, no significant pro-non-rural was recorded for Central Asia, Northern Africa, Southern Africa, Western Asia, Central America and Southern Europe. The inequalities observed across the countries are a pointer to the worsening health situation in the rural areas and it calls for urgent intervention.

In decomposing pro-rural inequality in the prevalence of diarrhoea in LMIC, compositional effects were found in factors such as neighbourhood SES, household wealth, wealth index, toilet type, child's age, maternal age and contribute greatly to the prevalence of diarrhoea across countries. This invariably suggests a thorough investigation into these variables as these will go a long way in reducing Diarrhoea occurrence among children of LMIC. Specifically, in countries such as India, Yemen, and Myanmar, diarrhoea is linked to neighbourhood SES, wealth index, maternal education, and unimproved toilet types as supported by several studies [41, 51,52]. Many of these countries are densely populated with a higher proportion of women with low socioeconomic status.

\section{Limitations of the study}

This study has some key strengths. The use of nationally representative data generated from standardised methods in 57 LMIC gave credibility to the findings of this study in terms of generalizability across countries. The study also presented a clear pattern of diarrhoea prevalence among U5C in LMIC. One of the drawbacks in the current study was that diarrhoea morbidities were measured based on individual self-reported information which may be subject to recall bias and under-reporting and thus, distorts data quality. However, the data originators ensured the reduction of such errors during data collection. Also, the timing of data collection which vary in the studied countries may result in a bias in the comparison of diarrhoea prevalence which occurred at different periods. Besides, the cross-sectional nature of the design of the study restricts the ability to adequately establish causality and determine how rural and non-rural disparities developed over time. Moreover, the definition and categorisation of rural and non-rural areas based on certain criteria differs across countries and could limit cross-country comparisons.

\section{Conclusions}

Our study shows significant rural-non-rural differences in diarrhoea prevalence in LMIC. The prevalence of diarrhoea was highest among children whose mothers reside in rural areas and has been linked to neighbourhood-level and individual-level factors. We found significant individual-level and community-level factors associated with pro-rural inequalities in many countries. Tackling childhood diarrhoea is not dependent on advances in technology but the adoption of interventions of proven efficacy that would further help reduce the burden of childhood diarrhoea and mortality. Sustainable intervention measures that are tailored to country-specific needs could offer a better approach to solving rural-non-rural gaps in diarrhoea prevalence in LMIC. Nonetheless, the odds of diarrhoea was higher among non-rural children in some countries. Further research is needed in this regard. However, the reasons could be ascribed to poor hygiene and sanitation in nonrural areas. More so, there are non-rural areas with slums, in which case the slums could have been categorized as non-rural areas. Of concern is also the type of food available to children in non-rural areas.

Public health and community efforts should focus on promoting hygiene programs and intervention such as hand washing, cleaning of toilet and proper disposal of waste in addition to provision of employment opportunities to women.. This calls for the formulation of effective interventions and policies that recognizes the heterogeneity of rural and non-rural communities. There is the need to formulate regional-specific policies, rather than generalised measures, in reducing the gap in ruralnon-rural diarrhoea burden. Also, intervention measures that focus on the redistribution of wealth, better access to improved sanitation among others will go a long way in reducing regional inequalities in childhood diarrhoea.

\section{Abbreviations \\ Cl: Confidence Interval; DHS: Demographic and Health Survey; IRB: Institutional Review Board; LMIC: Low- And Middle-Income Countries; PSU: Primary Sample Unit; RD: Risk Difference; SES: Socioeconomic Status; U5C: Under-Five Children; UNICEF: United Nations International Children's Emergency Fund; WHO: World Health Organization}

\section{Acknowledgements \\ The authors are grateful to ICF Macro, USA, for granting the authors the request to use the DHS data. The authors appreciate the logistic supports provided by the Consortium for Advanced Research and Training in Africa (CARTA) during his fellowship at the University of Warwick. CARTA is jointly led by the African Population and Health Research Center and the University of the Witwatersrand and funded by the Carnegie Corporation of New York (Grant No--B 8606.R02), Sida (Grant No:54100029), and the DELTAS Africa Initiative (Grant No: 107768/Z/15/Z).}

\section{Authors' contributions}

AFF conceptualised, designed the study, curated and analysed the data. AFF, FFO, OM, ASA, OSF and OAU contributed to literature search, figures, data interpretation, writing of the manuscript. All authors have read and approved the manuscript.

Funding

The authors received no funding for this study. 


\section{Availability of data and materials}

The data supporting this article is available at http://dhsprogram.com.

\section{Declarations}

\section{Ethics approval and consent to participate}

This study was based on the analysis of openly available secondary data. The Institutional Review Board (IRB) of Inner City Fund (ICF) International Macro at Fairfax, Virginia in the USA reviewed and approved the MEASURE Demographic and Health Surveys Project Phase III. The 2010-2018 DHS's are categorized under that approval. The Institutional Review Board (IRB) of Inner City Fund (ICF) International Macro complied with the United States Department of Health and Human Services requirements for the "Protection of Human Subjects" (45 CFR 46). Written informed consent was obtained from every study participant before participation and all information was collected without identifiers and kept confidentially. Inner City Fund (ICF) International Macro permitted the authors with authorisation number 140625 to use the data. The full details of the ethical approvals can be found at http://dhsprogram.com.

\section{Consent for publication}

Not applicable.

\section{Competing interests}

The authors declare that they have no competing interests.

\section{Author details}

'Department of Epidemiology and Medical Statistics, Faculty of Public Health, College of Medicine, University of Ibadan, Ibadan, Nigeria. ${ }^{2}$ Division of Health Sciences, Populations, Evidence and Technologies Group, Warwick Medical School, University of Warwick, Coventry, UK. ${ }^{3}$ Division of Population and Behavioural Studies, School of Medicine, University of St Andrews, Fife, UK. ${ }^{4}$ Department of Demography and Social Statistics, Faculty of Social Sciences, Obafemi Awolowo University, Ile-lfe, Nigeria. ${ }^{5}$ Department of Environmental Health Sciences, Faculty of Public Health, College of Medicine, University of Ibadan, Ibadan, Nigeria. ${ }^{6}$ Techmodia, London, West Sussex, UK. ${ }^{7}$ Portsmouth Business School, Faculty of Business and Law, University of Portsmouth, Portsmouth, UK.

\section{Received: 21 August 2020 Accepted: 11 March 2021} Published online: 23 March 2021

\section{References}

1. Melese B, Paulos W, Astawesegn FH, Gelgelu TB. Prevalence of diarrheal diseases and associated factors among under-five children in Dale District, Sidama zone, southern Ethiopia: a cross-sectional study. BMC Public Health. 2019;19:1-10.

2. Aziz FAA, Ahmad NA, Aznuddin M, Razak A, Omar M, Kasim NM, et al. Prevalence of and factors associated with diarrhoeal diseases among children under five in Malaysia : a cross-sectional study 2016. BMC Public Health. 2018;18:1-8.

3. Bitew BD, Woldu W, Gizaw Z. Childhood diarrheal morbidity and sanitation predictors in a nomadic community. Ital J Pediatr. 2017;43:1-8.

4. Fufa KW, Gebremedhin GB, Gebregergs GB, Mokonnon MT. Assessment of Poor Home Management Practice of Diarrhea and Associated Factors among Caregivers of Under-Five Years Children in Urban and Rural Residents of Doba Woreda, Ethiopia: Comparative Cross-Sectional Study. Int. J. Pediatr. [Internet]. Hindawi; 2019 [cited 2019 Aug 7];2019:1-12. Available from: https://www.hindawi.com/journals/ijpedi/2019/8345245/

5. Nilima, Kamath A, Shetty K, Unnikrishnan B, Kaushik S, Rai SN. Prevalence, patterns, and predictors of diarrhea: A spatialoral comprehensive evaluation in India 11 Medical and Health Sciences 1117 Public Health and Health Services. BMC Public Health [Internet]. BioMed Central Ltd.; 2018 [cited 2020 Apr 12];18:1288. Available from: https://bmcpublichealth.biomedcentral. com/articles/https://doi.org/10.1186/s12889-018-6213-z

6. WHO. Diarrhoeal Disease [Internet]. Geneva; 2017. Available from: http:// www.who.int/ mediacentre/factsheets/fs330/en/.

7. WHO. Diarrhoeal disease [Internet]. 2017 [cited 2019 Aug 7]. Available from: https://www.who.int/news-room/fact-sheets/detail/diarrhoeal-disease

8. Kattula D, Francis MR, Kulinkina A, Sarkar R, Mohan VR, Babji S, et al. Environmental predictors of diarrhoeal infection for rural and urban communities in south India in children and adults. Epidemiol. Infect [Internet]. 2015 [cited 2019 Aug 7];1-12. Available from: http://www. cmcwtrl.in/publications/Epidemiology-Infection.pdf

9. Sarker AR, Sultana M, Mahumud RA, Ali N, Huda TM. Salim uzzaman M, et al. economic costs of hospitalized diarrheal disease in Bangladesh: a societal perspective. Glob. Heal. Res. Policy. 2018;3(1):1-12. https://doi.org/10.1186/ s41256-017-0056-5.

10. Ahs JW, Tao W, Löfgren J, Forsberg BC. Diarrhoeal Diseases in Low- and Middle-Income Countries: Incidence, Prevention and Management. Open Infect. Dis. J. [Internet]. 2010 [cited 2019 Aug 20];4:113-124. Available from: https://pdfs.semanticscholar.org/0096/6b7bb3a3a78dd597e987a81 cc8cb6a12b518.pdf

11. Mokomane M, Kasvosve I, de Melo JMP E, DMG. The global problem of childhood diarrhoeal diseases: emerging strategies in prevention and management Margaret. Ther Adv Vacc. 2018;9:259-61.

12. Global Burden of Disease Collaborative Network (GBD). Global Burden of Disease Study 2016 (GBD 2016) Results. Seattle: Institute for Health Metrics and Evaluation; 2017.

13. WHO/UNICEF. Ending Preventable Child Deaths from Pneumonia and Diarrhoea by 202e5. Geneva, Switzerland; 2013.

14. Fagbamigbe AF, Morakinyo OM, Abatta E. Analysis of Regional Variations in Influence of Household and Environmental Characteristics on Prevalence of Diarrhoea among Under-Five Children in Nigeria. Ann Med Heal. Sci Res. [Internet]. 2017;7:119-130. Available from: http://www.amhsr.org/archive/a mhsr-volume-7-issue-3-may-2017.html

15. Akinyemi IA, Fagbamigbe AF, Omoluabi E, Agunbiade OM, Adebayo SO. Diarrhoea management practices and child health outcomes in Nigeria: subNational Analysis. Adv. Integr. Med. [internet]. Elsevier Ltd; 2018;5:15-22. Available from: http://linkinghub.elsevier.com/retrieve/pii/S2212958817300101

16. Carvajal-vélez L, Amouzou A, Perin J, Maïga A, Tarekegn H, Akinyemi IA, et al. Diarrhea management in children under five in sub-Saharan Africa : does the source of care matter? A countdown analysis. BMC Public Health. 2016;16:1-14.

17. Shati AA, Khalil SN, Asiri KA, Alshehri AA, Deajim YA, Al-Amer MS, et al. Occurrence of diarrhea and feeding practices among children below two years of age in southwestern Saudi Arabia. Int J Environ Res Public Health. 2020;17:1-10.

18. Dairo M, Ibrahim TF, Salawu AT. Prevalence and determinants of diarrhoea among infants in selected primary health centres in Kaduna north local government area, Nigeria. Pan Afr Med J. 2017;28:109.

19. Ahmadipour S, Mohsenzadeh A, Alimadadi H, Salehnia M, Fallahi A. Treating viral diarrhea in children by probiotic and zinc supplements. Pediatr Gastroenterol Hepatol Nutr. 2019;22(2):162-70. https://doi.org/10.5223/ pghn.2019.22.2.162.

20. Mohammed Al, Zungu L. Environmental health factors associated with diarrhoeal diseases among underfive children in the Sebeta town of Ethiopia. South African J Infect Dis AOSIS. 2016;31:122-9.

21. ICF International. Demographic and health survey: sampling and household listing manual [internet]. Calverton; 2012. Available from: https://www. dhsprogram.com/pubs/pdf/DHSM4/DHS6_Sampling_Manual_Sept2012_ DHSM4.pdf

22. Croft TN, Marshall AMJ, Allen CK. Guide to DHS statistics [internet]. 2018. Available from: https://dhsprogram.com/pubs/pdf/DHSG1/Guide_to_DHS_ Statistics_DHS-7.pdf

23. National Population Commission(NPC)[Nigeria], ICF International. Nigeria Demographic and Health Survey 2018. Abuja, Nigeria, And Rockville, Maryland, USA; 2019.

24. Taffa N, Chepngeno G, Amuyunzu-Nyamongo M. Child Morbidity and Healthcare Utilization in the Slums of Nairobi, Kenya. J. Trop. Pediatr. [Internet]. 2005 [cited 2020 Apr 12];51:1-6. Available from: https://academic. oup.com/tropej/article/51/5/279/1690164

25. Minh A, Muhajarine N, Janus M, Brownell M, Guhn M. A review of neighborhood effects and early child development: How, where, and for whom, do neighborhoods matter? Heal. Place. Elsevier Ltd; 2017. p. 155-174.

26. Lahariya C, Paul VK. Burden, differentials, and causes of child deaths in India. Indian J. Pediatr, 21. 2010:1312.

27. Yongsi HBN. Pathogenic Microorganisms Associated With Childhood Diarrhea in Low-and-Middle Income Countries: Case Study of Yaoundé Cameroon. Int. J. Environ. Res. Public Health [Internet]. Molecular Diversity Preservation International; 2008 [cited 2020 Apr 12];5:213-229. Available from: http://www.mdpi.com/1660-4601/5/4/213 
28. Guarino A, Giannattasio A, Lo Vecchio A. Management of children with prolonged diarrhea. F1000Research. Faculty of 1000 Ltd; 2016. p. 206.

29. Mosley WH, Chen LCLC. An analytical framework for the study of child survival in developing countries. Popul. Devp Rev. [internet]. Popul Council; 1984;10:24-45. Available from: http://www.jstor.org/stable/2807954?origin= crossref

30. Powers DA, Yoshioka H, Yun M. Mvdcmp: multivariate decomposition for nonlinear response models. Stata J. 2011;11(4):556-76. https://doi.org/10.11 77/1536867X1201100404

31. Oaxaca R. Male-female wage differentials in urban labor markets. Intl Econ Rev. 1973;14(3):693-709. https://doi.org/10.2307/2525981.

32. Hlavac M. oaxaca: Blinder-Oaxaca Decomposition in R [Internet]. R Packag. version 0.1.4. 2018. p. 1. Available from: https://cran.r-project.org/package= oaxaca

33. Blinder AS. Wage discrimination: reduced form and structural estimates. J Hum Resour. 1973;8(4):436-55. https://doi.org/10.2307/144855.

34. Fairlie RW, Robb AM. Why Are Black-Owned Businesses Less Successful than White-Owned Businesses? The Role of Families, Inheritances, and Business Human Capital. J Labor Econ. 2007;25(2):289-323. https://doi.org/10.1086/51 0763.

35. Fairlie RW. Addressing Path Dependence and Incorporating Sample Weights in the Nonlinear Blinder-Oaxaca Decomposition Technique for Logit, Probit and Other Nonlinear Models. Stanford; 2017. Report No.: 17-013.

36. Fairlie RW. An Extension of the Blinder-Oaxaca Decomposition Technique to Logit and Probit Models [Internet]. Yale; 2003. Report No.: 873. Available from: http://ssrn.com/abstract=497302

37. Fairlie RW. An extension of the Blinder-Oaxaca decomposition technique to logit and probit models. J Econ Soc Meas. 2005;30(4):305-16. https://doi org/10.3233/JEM-2005-0259.

38. Jann B. Fairlie: Stata module to generate nonlinear decomposition of binary outcome differentials [Internet]. 2006 [cited 2020 Apr 6]. p. 1. Available from: http://ideas.repec.org/c/boc/bocode/s456727.html

39. Fairlie RW. The absence of the African-American owned business: an analysis of the dynamics of self-employment. J Labor Econ. 1999;17(1):80108. https://doi.org/10.1086/209914

40. Norman G, Pedley S, Takkouche B. Effects of sewerage on diarrhoea and enteric infections: a systematic review and meta-analysis. Lancet Infect. Dis. [Internet]. 2010 [cited 2019 Aug 20];10:536-544. Available from: https:// linkinghub.elsevier.com/retrieve/pii/S1473309910701237

41. GBD 2016 Diarrhoeal Disease Collaborators. Estimates of the global, regional, and national morbidity, mortality, and aetiologies of diarrhoea in 195 countries: a systematic analysis for the Global Burden of Disease Study 2016. Lancet Infect. Dis. [Internet]. Elsevier; 2018 [cited 2019 Jul 1];18:12111228. Available from: https://www.thelancet.com/journals/laninf/article/ PIIS1473-3099(18)30362-1/fulltext

42. Acácio S, Mandomando I, Nhampossa T, Quintó L, Vubil D, Sacoor C, et al. Risk factors for death among children 0-59 months of age with moderateto-severe diarrhea in Manhiça district, southern Mozambique. BMC Infect Dis. 2019;19:1-14.

43. Agegnehu MD, Bewket Zeleke L, Goshu YA, Ortibo YL, Mehretie Adinew Y. Diarrhea Prevention Practice and Associated Factors among Caregivers of Under-Five Children in Enemay District, Northwest Ethiopia. J. Environ. Public Health [Internet]. Hindawi; 2019 [cited 2019 Aug 20];2019:1-8. Available from: https://www.hindawi.com/journals/ jeph/2019/5490716/

44. Li R, Lai Y, Feng C, Dev R, Wang Y, Hao Y. Diarrhea in under five year-old children in Nepal: a spatiotemporal analysis based on demographic and health survey data. Int J Environ Res Public Health. 2020;17.

45. Abuzerr S, Nasseri S, Yunesian M, Hadi M, Mahvi AH, Nabizadeh R, et al. Prevalence of diarrheal illness and healthcare-seeking behavior by agegroup and sex among the population of Gaza strip: a community-based cross-sectional study. BMC Public Health. 2019;19:1-10.

46. Finlay JE, Özaltin E, Canning D. The association of maternal age with infant mortality, child anthropometric failure, diarrhoea and anaemia for first births: evidence from 55 low- and middle-income countries. BMJ Open. 2011;1(2):e000226. https://doi.org/10.1136/bmjopen-2011000226

47. Fikire A, Ayele G, Haftu D. Determinants of delay in care seeking for diarrheal diseases among mothers/caregivers with under-five children in public health facilities of Arba Minch town, southern Ethiopia. PLoS One. 2020;15:1-16.
48. Takele K, Zewotir T, Ndanguza D. Risk factors of morbidity among children under age five in Ethiopia. BMC Public Health. 2019;19:1-9.

49. Bawankule $R$, Singh A, Kumar K, Shetye S. Does measles vaccination reduce the risk of acute respiratory infection (ARI) and diarrhea in children: a multicountry study? PLoS One. 2017;12:1-17.

50. Beyene SG, Melku AT. Prevalence of diarrhea and associated factors among under five years children in Harena Buluk Woreda Oromia region, south East Ethiopia. J Public Heal Int. 2018;1(2):9-26. https://doi.org/10.14302/issn.2 641-4538.jphi-18-2470

51. Bin Mohanna M, Al-Sonboli N. Prevalence of diarrhoea and related risk factors among children aged under 5 years in Sana'a, Yemen Hamdan. Hamdan Med J. 2017.

52. AkwasiKumi $\mathrm{K}$, JoshuaAmo A. Household wealth, residential status and the incidence of diarrhoea among children under-five years in Ghana. J Epidemiol Glob Health. 2015;6:131-40.

\section{Publisher's Note}

Springer Nature remains neutral with regard to jurisdictional claims in published maps and institutional affiliations.

\section{Ready to submit your research? Choose BMC and benefit from:}

- fast, convenient online submission

- thorough peer review by experienced researchers in your field

- rapid publication on acceptance

- support for research data, including large and complex data types

- gold Open Access which fosters wider collaboration and increased citations

- maximum visibility for your research: over $100 \mathrm{M}$ website views per year

At BMC, research is always in progress.

Learn more biomedcentral.com/submissions 